\title{
Inflammatory tinea capitis. a clinical case presentation treated with oral terbinafine
}

\section{Summary}

Tinea capitis is one of the most common dermatoses in the pediatric age. We present the case of a female patient of 6 years of age with inflammatory ringworm of the head or Querion of Celso caused by Microsporum canis. A brief review of the literature is made.

Keywords: tinea capitis, microsporum canis, dermatophyte
Volume I Issue 2 - 2017

\section{Antonio David Pérez-Elizondo,' Cristina Contreras-Guzmán, ${ }^{2}$ Maria Elena Ruíz-Pèrez ${ }^{2}$}

'Department of Dermatology, Autonomous University, Mexico ${ }^{2}$ Department of Dermatology, Maternal and Child Institute, Mexico

Correspondence: Antonio David Pérez-Elizondo, Head of External Consultation, Maternal and Child Institute of the State of Mexico Professor of the Chair of Dermatology, Autonomous University of the State of Mexico, Mexico,

Email antoniodavid64@gmail.com

\section{Introduction}

Dermatophytosis or ringworms are superficial mycoses produced by a set of filamentous fungi with the ability to invade and proliferate in keratinized tissue such as skin and adnexal structures. The genera most frequently involved in cutaneous pathology are Epidermophyton, Trichophyton and Microsporum. Undoubtedly, the so-called ringworm of the head is a condition of the child population, although it may appear in the neonatal period and in adults. It seems that the greater presence of fungistatic fatty acids in sebaceous secretion would be responsible for the resistance to infection in postpuberal age. Transmission may be through infection with infected animals, by close and close interpersonal contact, or through fomites. Risk factors are numerous families, low socioeconomic level, collection or overcrowding and coexistence with domestic animals. ${ }^{1,2}$

\section{Clinical case}

A 6-year-old female was attended in our Hospital, with no family or personal pathological history of interest for the current illness, except the close coexistence with dogs at home. It presents dermatosis located at the head of the one that involves the occipital area characterized by the presence of an extensive pseudoalopécica plate in "in band" with fragmented hairs or cut to different levels, some in small slender tufts interspersed with adherent escamocostrosas formations of color and bottom Slightly diffuse erythematosus. A bright, moist red-colored abscess with thick purulent material emission is observed (Figure 1). Physical examination is occasionally painful retroauricular and occipital adenopathy; there is no evidence of an attack on the general condition. Approximate evolution 2 months beginning with a process that resembles pityriasis capitis with progression towards the current picture. It was previously treated by a private physician for the alleged suspected diagnosis of bacterial folliculitis based on oral dicloxacillin at a usual dosage for 1 month in addition to $2 \%$ fusidic acid ointment applied twice a day for the same period of time without favorable therapeutic outcome.

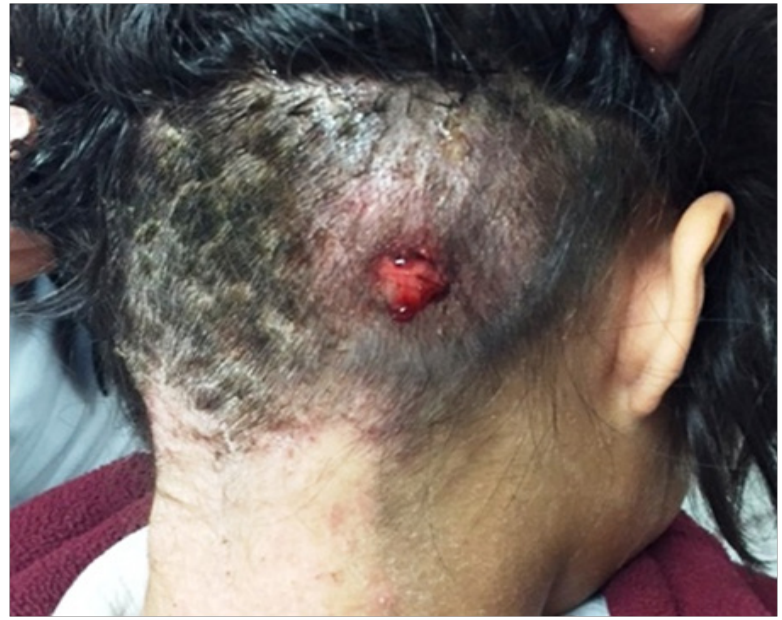

Figure I Extensive pseudoalopoeic plaque with inflammatory activity.

Direct examination was requested with potassium hydroxide and culture on Saboraud dextrose agar medium. Partial and branched hyaline hyphae were reported simulating a "Thai boat" compatible with Microsporum canis. By the tenth day of culture at room temperature the presence of velvety white or flat corrugated colonies becomes evident; On the reverse an intense yellow color is characteristic (Figures $2 \& 3$ ).

The diagnosis of inflammatory tinea capitis or also known as Querion de Celso was corroborated. The treatment was based on oral terbinafine at a rate of $125 \mathrm{mg}$ per day for 1 month in addition to the use of $2 \%$ ketoconazole shampoo during the daily bath under a gentle digital massage for 5 minutes. Therapy was effective with slow hair repopulation and reduction of the inflammatory reaction, without scarring after 2months (Figure 4). 


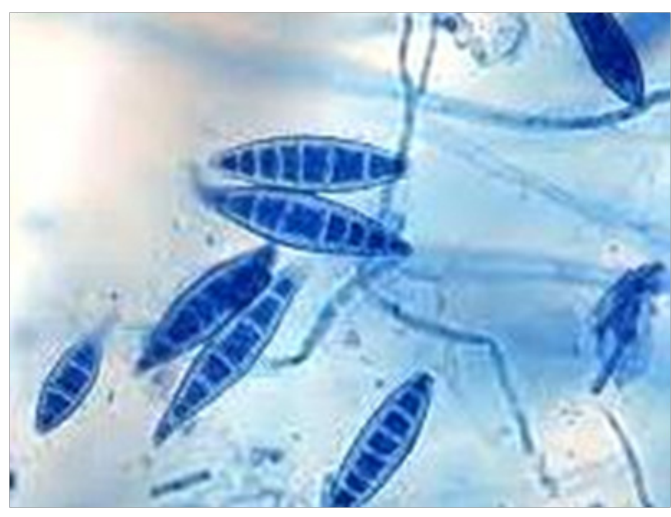

Figure 2 Articulated mud-shaped "Thai boat".

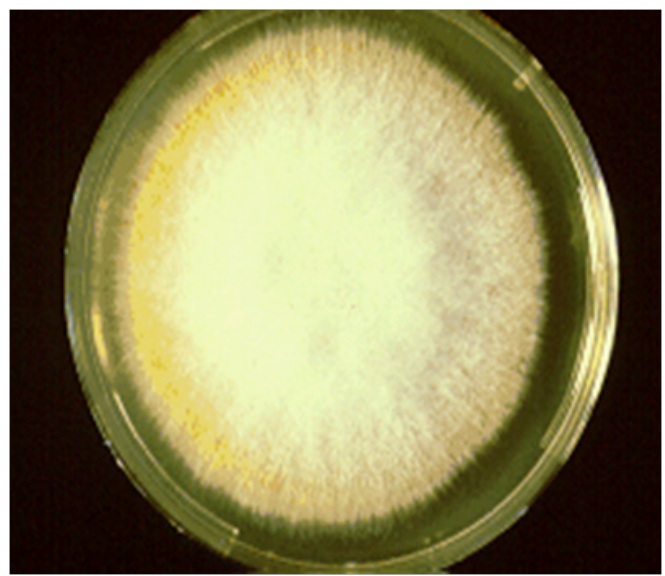

Figure 3 Flat velvety white colony in culture medium.

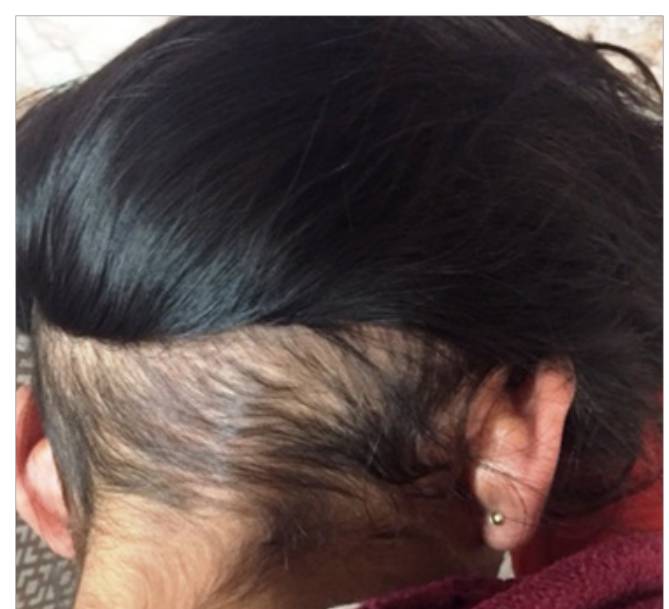

Figure 4 Clinical cure at 2 months of treatment.

\section{Commentary}

Tinea capitis is a common skin disease in the pediatric age, it is estimated that 3 to $8 \%$ of children in the United States of America are affected, especially those of Latino and African American ancestry have increased their incidence by more than $200 \%$ in the last 10 years.
Although there are great variations in age and gender according to the causative microorganism, the age peak is from 3 to 8 years, more common among males. Microsporum canis, a zoophilic dermatophyte of domestic pets is the most frequent responsible in Latin America, occurs the interpersonal transmission under the close and close physical contact conditioning epidemics in homes, orphanages, schools or hospitals. Trichophyton tonsurans is another common causal agent that unlike Microsporum canis has a high index of asymptomatic carriers with chronic subclinical infections that make it difficult to control the disease. According to Elewsky the role of contaminated objects is doubtful in cases produced by the latter. Several clinicalmorphological patterns of presentation are distinguished:

Microsporic tinea, in this fragmented arthroconidia are located around the hairy cuticle, parasite ectotrix, there are one or more lesioned circular pseudoalopécica lesions well delimited rojizodescamativas up to $6 \mathrm{~cm}$ in size. The hairs break within $3 \mathrm{~mm}$ of their emergence from the scalp.

Trichophytic tinea, the endotrix parasite in which arthroconidia is located inside the hair shaft replacing the intrapapillary keratin leaving the cortex intact. It is presented as several plates of smaller dimension, intermingled hairs of normal appearance with those cut to different levels, is the ring of the "black spots".

Querion of Celsus, is the inflammatory form of ringworm of the head with one or a few alopectic lesion plates occasionally painful with erythema, desquamation, meliceric crusts, pustules and abscesses, the sign of the "foam" consisting of the expression of Purulent material through the follicular orifices by compressing the affected fluctuating zone. The state of self immunity is high, the damage of the area involved results from the attempt to eliminate the responsible microorganism.

The treatment of choice is griseofulvin, other alternatives are oral imidazoles or oral terbinafine for 6 to 8 weeks. It is recommended 1 or 2 more months after obtaining the clinical and mycological cure with the aim of reducing recurrences. The case presented is shared with the purpose of identifying this frequent pathology in children and treating it in a timely and effective manner. ${ }^{3-6}$

\section{Acknowledgements}

None.

\section{Conflict of interest}

The author declares no conflict of interest.

\section{References}

1. Bonifaz A, Arenas R. Dermatofitosis, Revisión del ler. Consenso Nacional de Prevención, Diagnóstico y tratamiento de micosis superficiales. Facultad de medicina UNAM; 2001. p. 11-25.

2. Molina De, Soschin D, Bojórquez MA, et al. Granuloma tricofítico y Querión de Celso: Datos clínicos, micológicos e histopatológicos de nueve casos. Dermatología Rev Mex. 2002;46(1):15-22.

3. Padilla MC. Micosis superficiales. Rev Fac Med UNAM. 2003;46(4):134 137.

4. Padilla DMC. Tiña inflamatoria de la cabeza por Trichophyton tonsurans, comunicación de dos casos. Rev Cent Dermatol Pascua. 2000;9:172-176. 
5. Arenas R. Dermatología atlas, diagnóstico y tratamiento. segunda edición México: McGraw-Hill Interamericana; 1996. p. 324-334.
6. Lavalle P. Las dermatofitosis. Actualidades médicas y quirúrgicas. XI Jornadas Médicas Nacionales. In: Flores Q, editor. Tiña de la cabeza en el Centro Dermatológico Pascua de 1993 a 2002. México: 1968. p. 95-112. 